\title{
DIAGNOSIS AND REPAIR TECHNOLOGY OF DAMAGED ELEMENTS OF CASA AIRCRAFT
}

\author{
Michał Salacinski \\ Piotr Synaszko \\ Air Force Institute of Technology, Warsaw, Poland \\ Robert Olszak \\ Military Aviation Works No. 3, Deblin, Poland
}

\begin{abstract}
Recently Polish Air Force has been equipped with new types of aircraft. New aircraft have many elements made of composites. Composites enable increasing performance but also pose new challenges. One of these challenges is the necessity of repairing after damage. This paper presents the results of the non-destructive inspection (MIA, conductivity, optical measurement) of the C295 plane after damage. Some parts made of composites and metal were damaged. In this paper, the authors propose a technology of repairing damaged parts.
\end{abstract}

\section{INTRODUCTION}

Polish Air Force uses a lot of types of aircraft, which are exploited according to "safe life" or "damage tolerance" philosophy or a combination of both. After an accident, inspectors have to take a decision on the plane's airworthiness.

This is why at the AFIT, as all over the world, scientists work on nondestructive testing, investigating aircraft structures [1]. New NDT methods are used to find failures. Based on their experience, scientists have to decide, depending on the size of the failure, whether to continue exploitation, repair an aircraft's part or disable it. If they know that a part is to be repaired, specialists have to develop a technology of repairing. After the part has been repaired, NDT methods are used to check its condition [2]. During the following exploitation, structure condition monitoring is needed, so scientists have to decide which methods NDT or SHM will be more suitable for this purpose.

The Polish military plane - CASA caught fire. The AFIT researchers have investigated the structure using the NDT methods and, together with specialists form WZL-3, have proposed the repair method.

\section{AREA OF DAMAGE}

During take-off, the breaks broke down and got blocked, which caused burning of the composite panels. The fire was not big, but the composite panels and the metal longeron as well as the elements inside the left gear's deflector required nondestructive inspection and repair. 


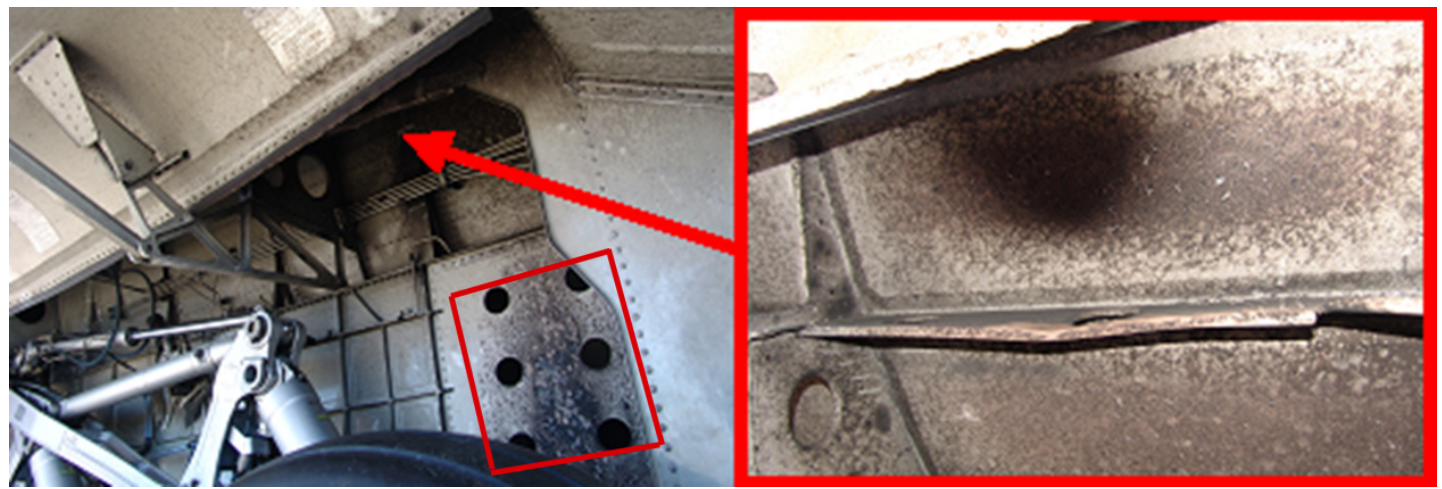

Fig. 1. Area of interesting

\section{NDT METHODS AND EQUIPMENT USED DURING INSPECTION}

The investigated panel is a CFRP sandwich structure. Tests for disbonds between the core and the skin were made. The elementary visual inspection provided information about a large area of disbond. Next step was a quantification with the Bond Master equipment, and the manual Tap Testing (for the confirmation of the results).

The second object under investigation was the longeron (Fig. 1). For the longeron, the conductivity inspection was performed with the Phasec 2200 equipment.

There was discovered a relation between temperature and conductivity of aluminum alloy, as well as between conductivity and strength [3].

a)

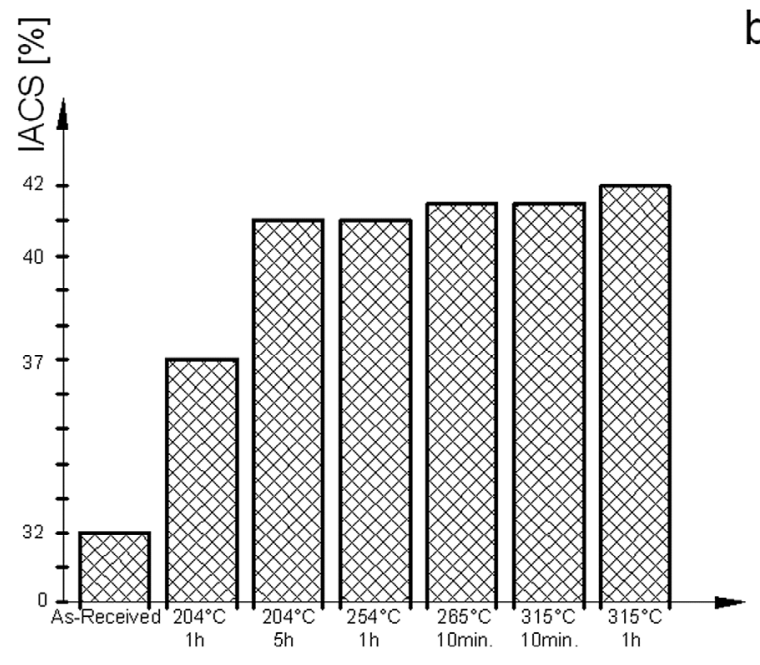

b)

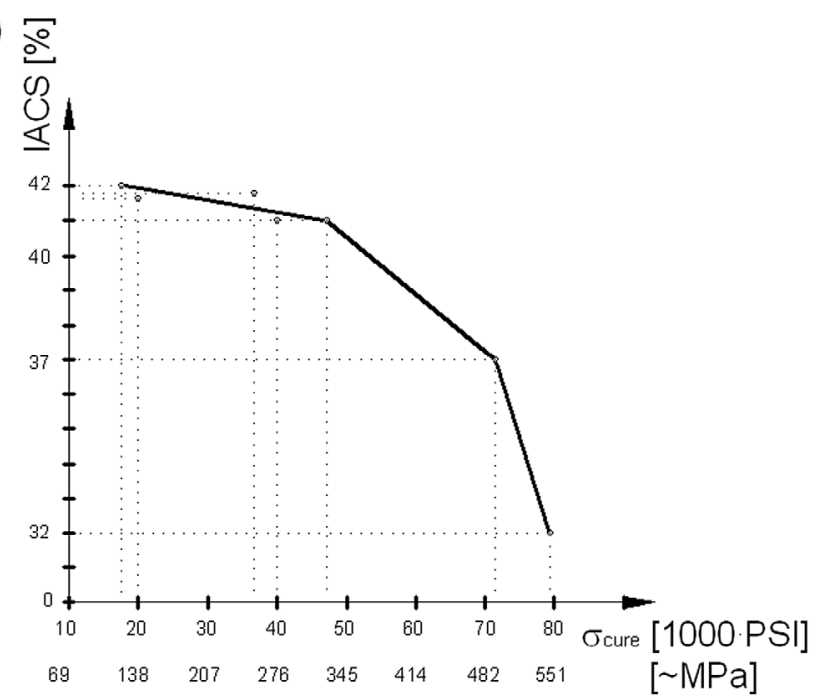

Fig. 2. The dependence aluminum alloy's conductive-module

In the figure below, the blue color represents a "good" area. Other colors represent higher conductivity. 


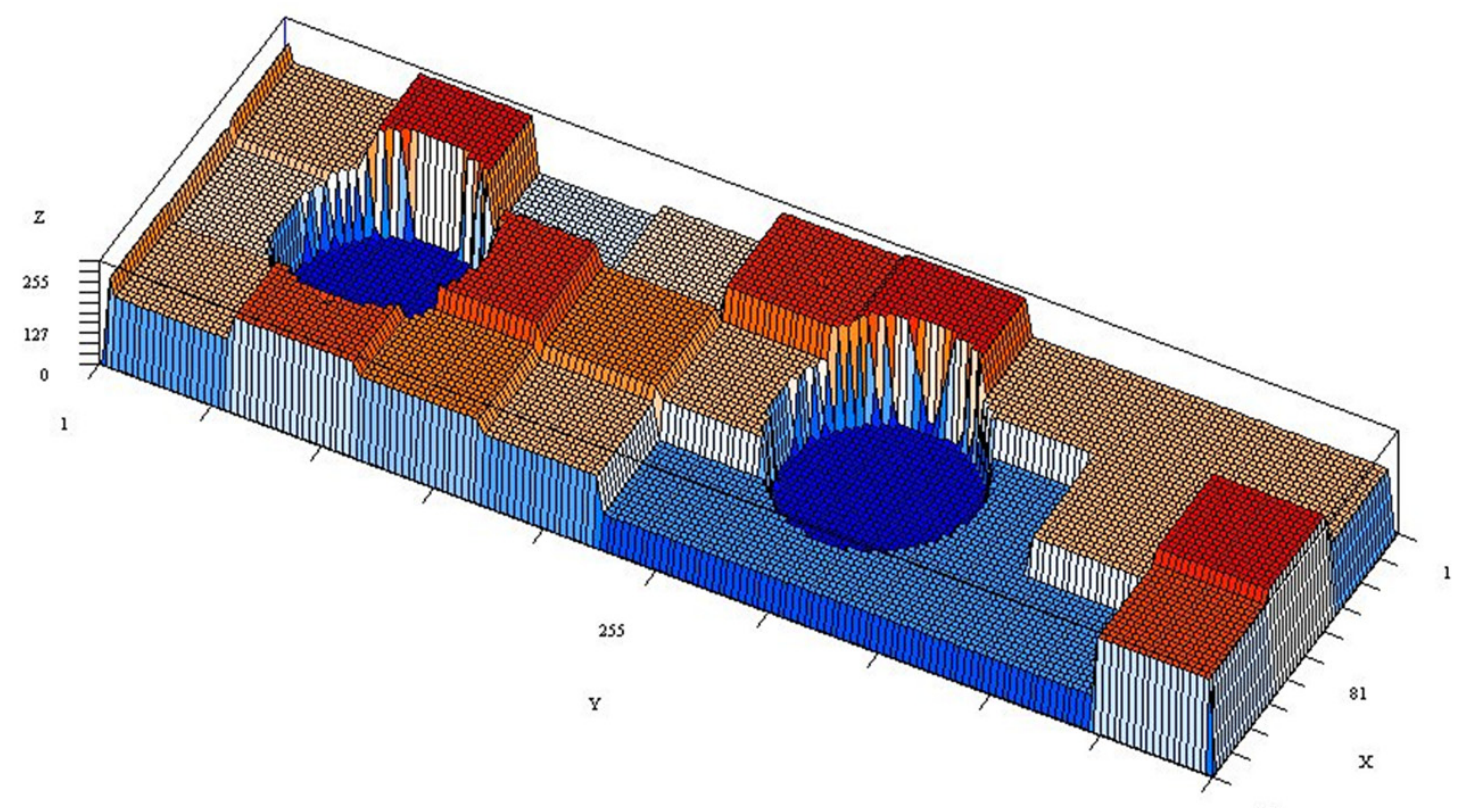

Fig. 3. Map of conductivity of longeron in damage area

Afterwards, optical measurements with the ATOS equipment were made.

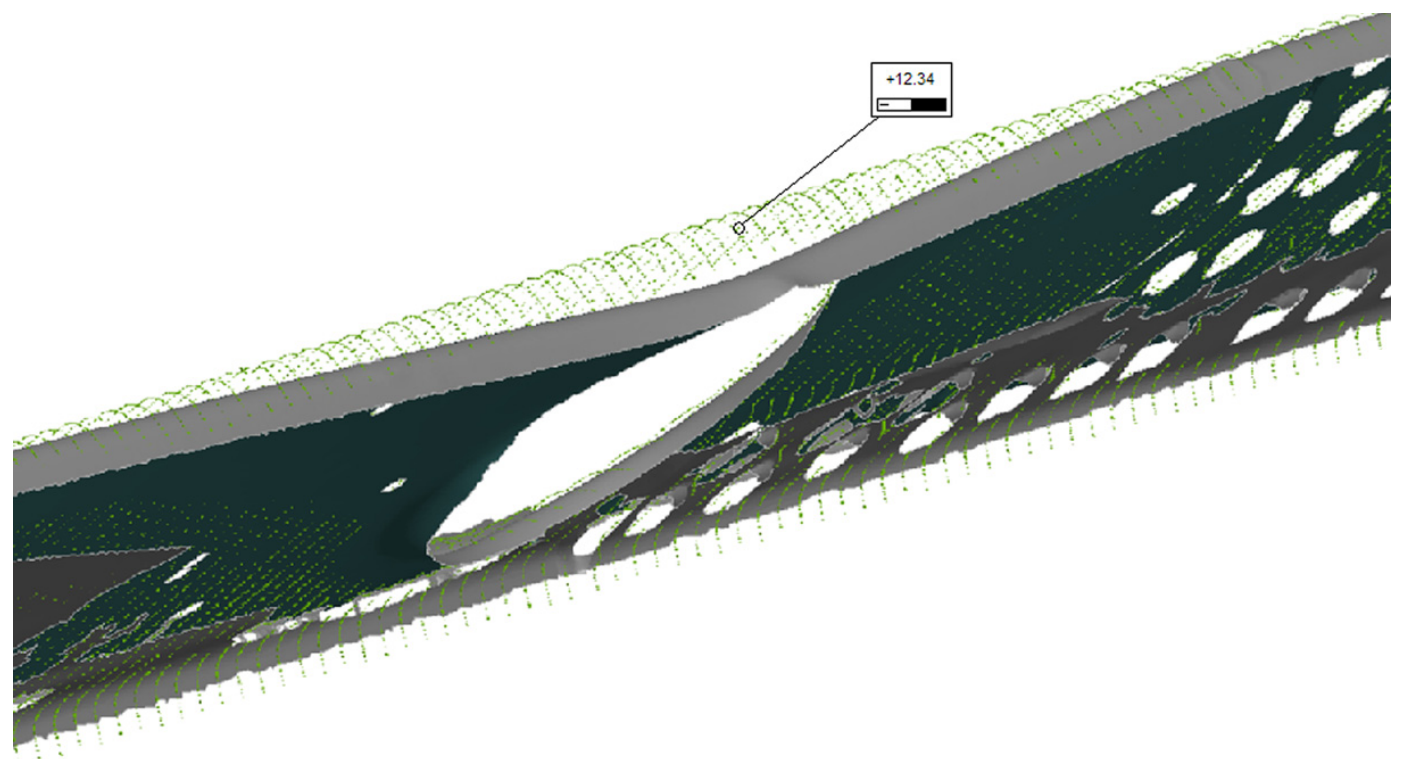

Fig. 4. Displacement of longeron in damage area

In the picture above (Fig.4), the deformation of the longeron caused by the heat treatment can be seen.

\section{REPAIR PROPOSALS}

Based on performances obtained from NDT, the technology of repairing the longeron and composite elements was developed.

Repair of composite elements.

The fire caused failure in three composite elements, but this paper focuses on the vertical panel only (Fig. 1). 


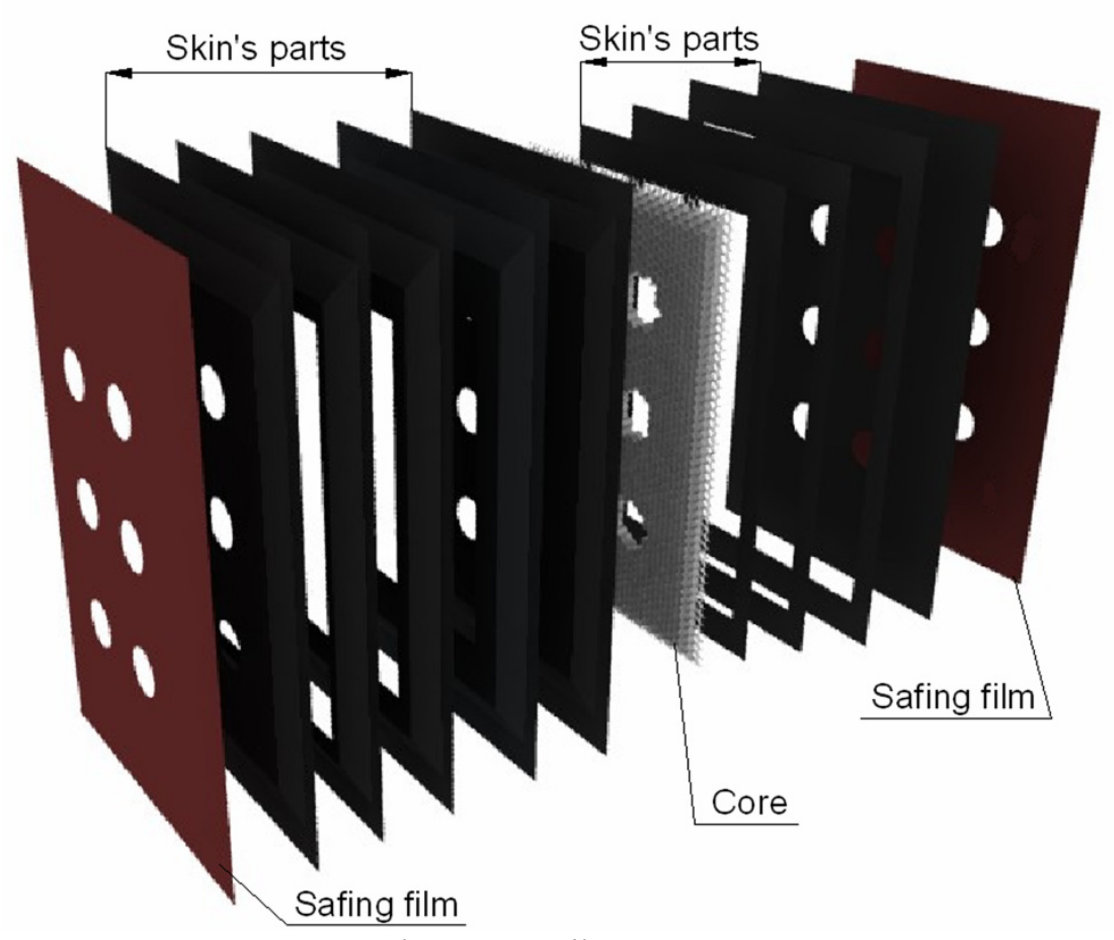

Fig. 5. Panel's structure

The failure found should be repaired by different methods: replacing the damaged part with a new one, filling up with resin gaps between the skin and the core, removing and reconstructing the damaged panel's parts: the skin, core and protective layer.

The latter is the best method. It is a popular method, especially when the structure is resistant to fast changes of temperature in a wide range. Resin used in these composites is resistant to high temperature (up to $\sim 130^{\circ} \mathrm{C}$ ), however, the temperature during the cure is still higher $\left(\sim 180^{\circ} \mathrm{C}\right)$. In these cases, temperature is usually reduced and time of cure is extended accordingly.

The CASA's composite elements are performed from prepregs. Prepreg is a fibrous material preimpregnated with a synthetic resin and hardener, which after mixing begin to react. This is why prepregs are kept at low temperatures just after impregnating until being used, because it slows down chemical reaction.

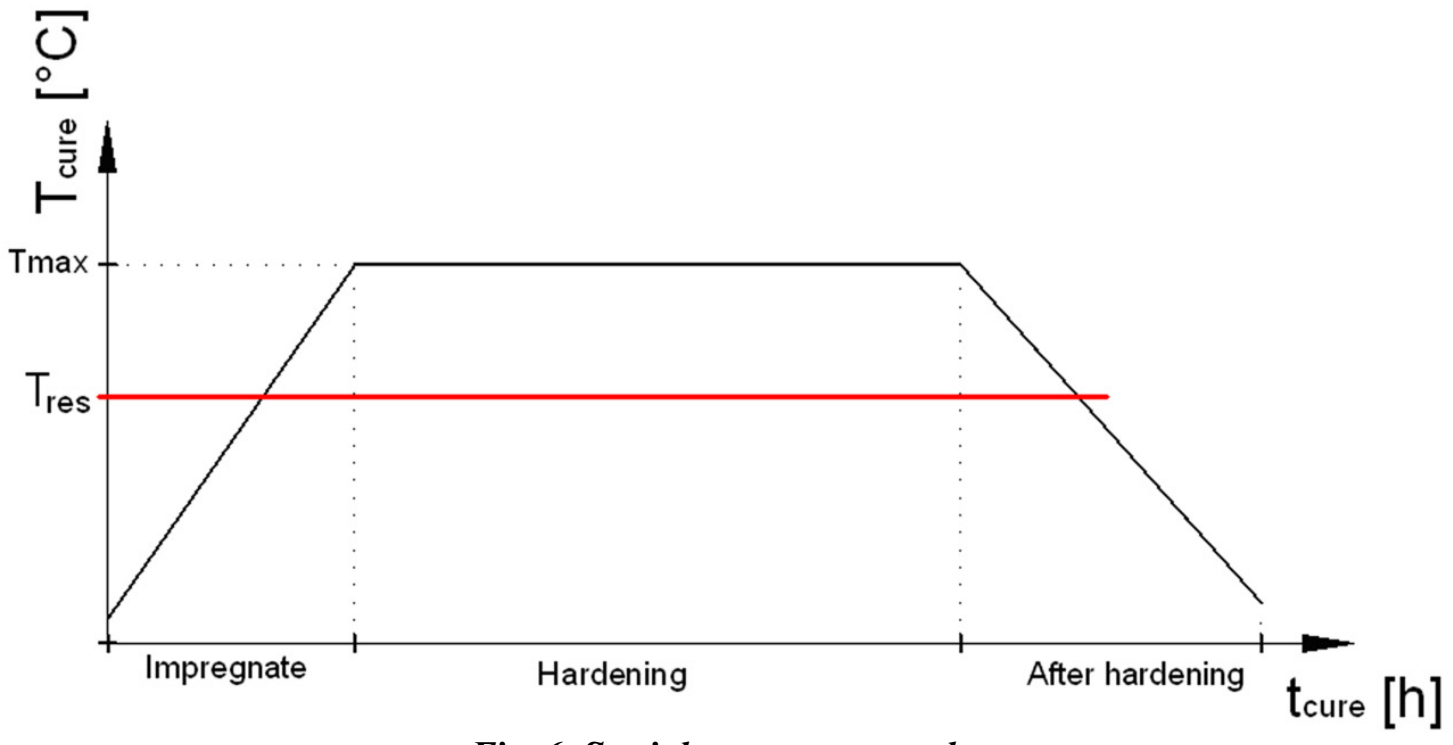

Fig. 6. Straight-ramp cure cycle 
Sometimes prepregs contain other components which slow down chemical reaction. These components are deactivated at the maximum temperature during the cure. Immediate refrigeration of prepregs causes only the preliminary impregnation, the proper impregnation occurs during the first stage of the temperature cycle - in this first step of the cure: temperature grows and viscosity decreases. Next step is hardening, usually at constant high temperature, followed by cooling down.

That is why damage reconstructing using prepreg is impossible, as the fibrous material will not be sufficiently impregnated, and the matrix will not have required properties [4].

So, in such cases, composite elements are repaired using the wet layup method. It is important that the patch has properties equivalent to the original structure properties after curing.

\subsection{Resin}

CASA's documentation contains basic information about original materials - prepregs. So paper focuses on the application of adequate materials and the method of cure.

Based on the documentation, it is known that the panel's temperature resistance is $130^{\circ} \mathrm{C}$, and that the prepreg's maximum cure temperature is $180^{\circ} \mathrm{C}$.
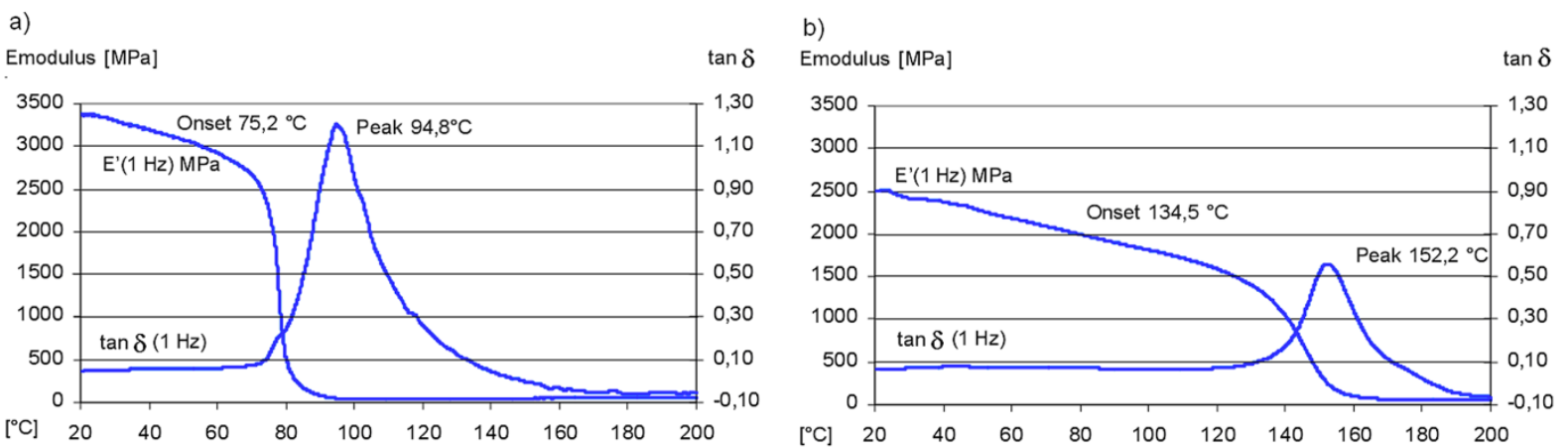

Fig. 7. Equivalent epoxy matrix's dynamic mechanic properties (data manufacturer): a) heat treatment $15 \mathrm{~h}$ in $50^{\circ} \mathrm{C}$, b) heat treatment $5 \mathrm{~h}$ in $160^{\circ} \mathrm{C}$

The Federal Aviation Authority gives information about temperature cycles at two acceptable extreme temperatures.

Based on the above, it is possible to determine the temperature cycle parameters of the patch at the safe temperature.

a)

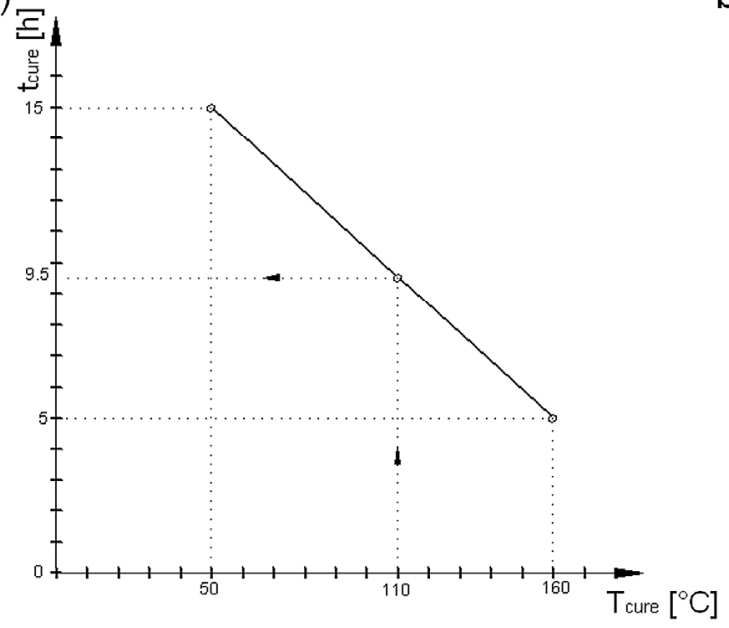

b)

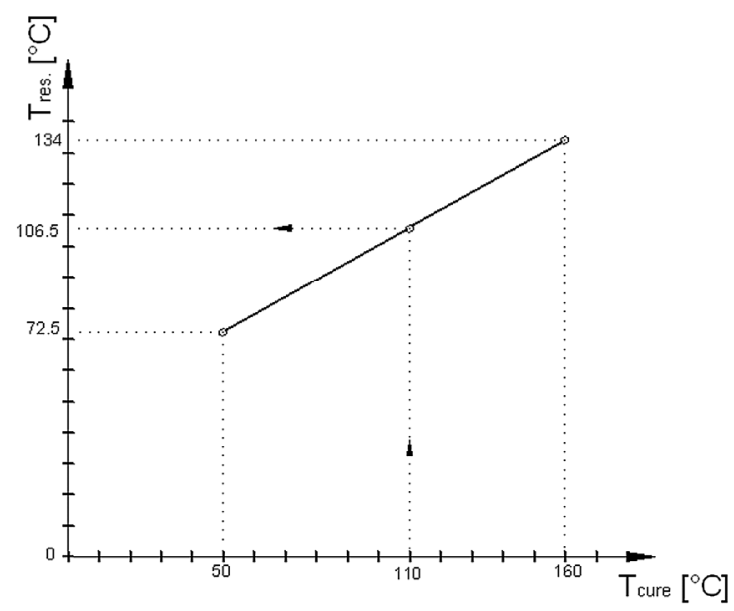

Fig. 8. Regress of parameters cure 


\subsection{Reinforcing}

Types of fibrous material and lay-up directions are according to CASA's documentation.

\subsection{Method of patching}

The fire caused disbonding between the skin and the core. The first step is removing the damaged skin and cleaning the core. The corner is a notch, so the corners radiuses should be increased.

a)

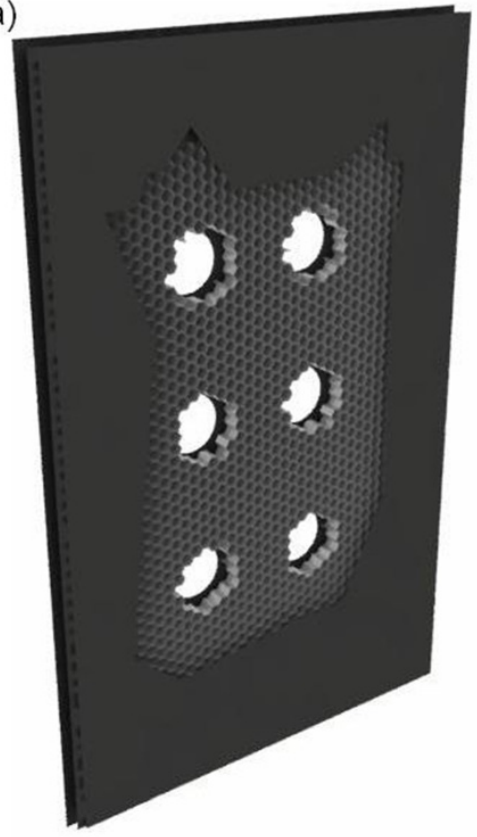

b)

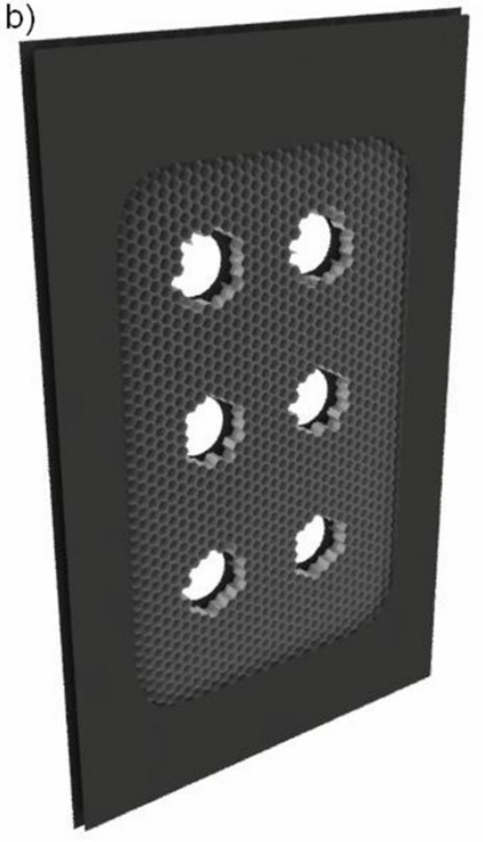

Fig. 9. Reduction influence of the notch, a) before tooling, b)after tooling

\section{PROCEDURE OF REPAIR}

Chamfer of the original edges makes it possible to bond the adequate patch layers. Used in carrier elements, chamfer has the width of $60 \mathrm{~mm}$ and the thickness of $1 \mathrm{~mm}$.

Big gaps in the core are filled up with the real core, in this case Hex-core or Ox-core, while smaller gaps are filled up with a composition of resin, microballoons and silicone (AEROSIL $® 202$ ).

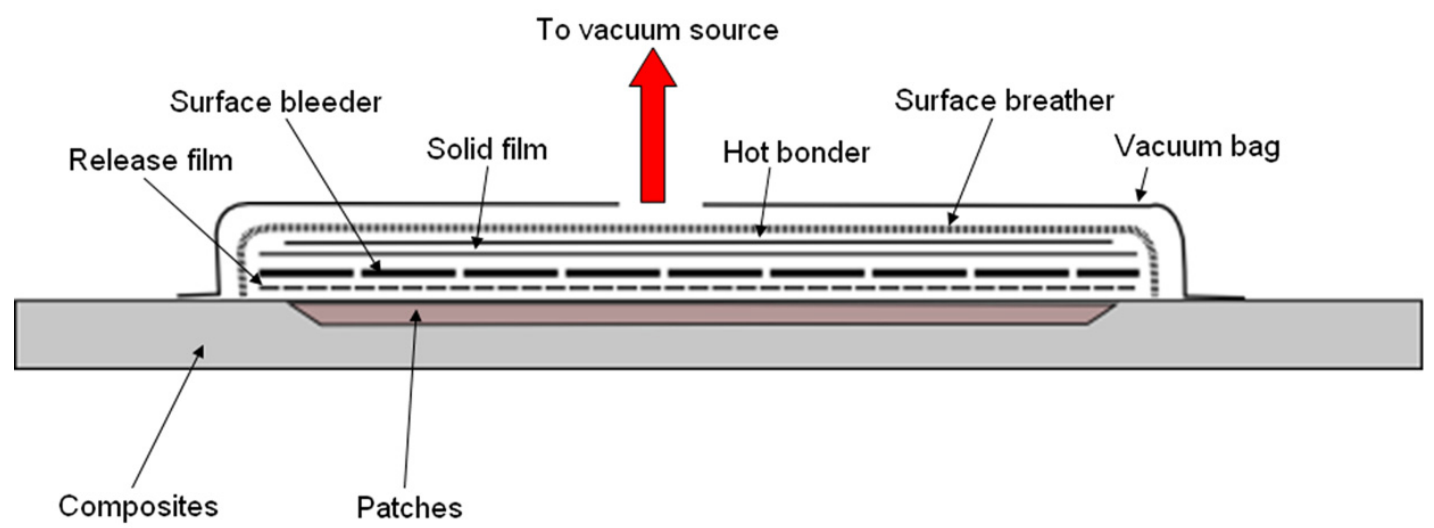

Fig. 10. Method repair and cure equipment 
The resin cure requires temperature treatment and compression. For temperature treatment a hot bonder is used, and for compression a vacuum-bag is used. Temperature and vacuum compression are computer controlled.

The properties of the vacuum-bag assures quality of the patch. Release film is the most important element because it ensures the right reinforcement - resin ratio in the patch.

After curing the quality of bonding and the patch are checked by NDT specialists.

\section{REPAIR OF METAL LONGERON}

The longeron is performed from aluminum alloy and that is why the repair technology of this part was developed by airframes specialist.

Based on NDT performance and the diagram (Fig. 2), the repair technology of riveting the alloy fastener to the longeron was developed. The properties of the alloy are same as those of the longeron (Fig. 11).

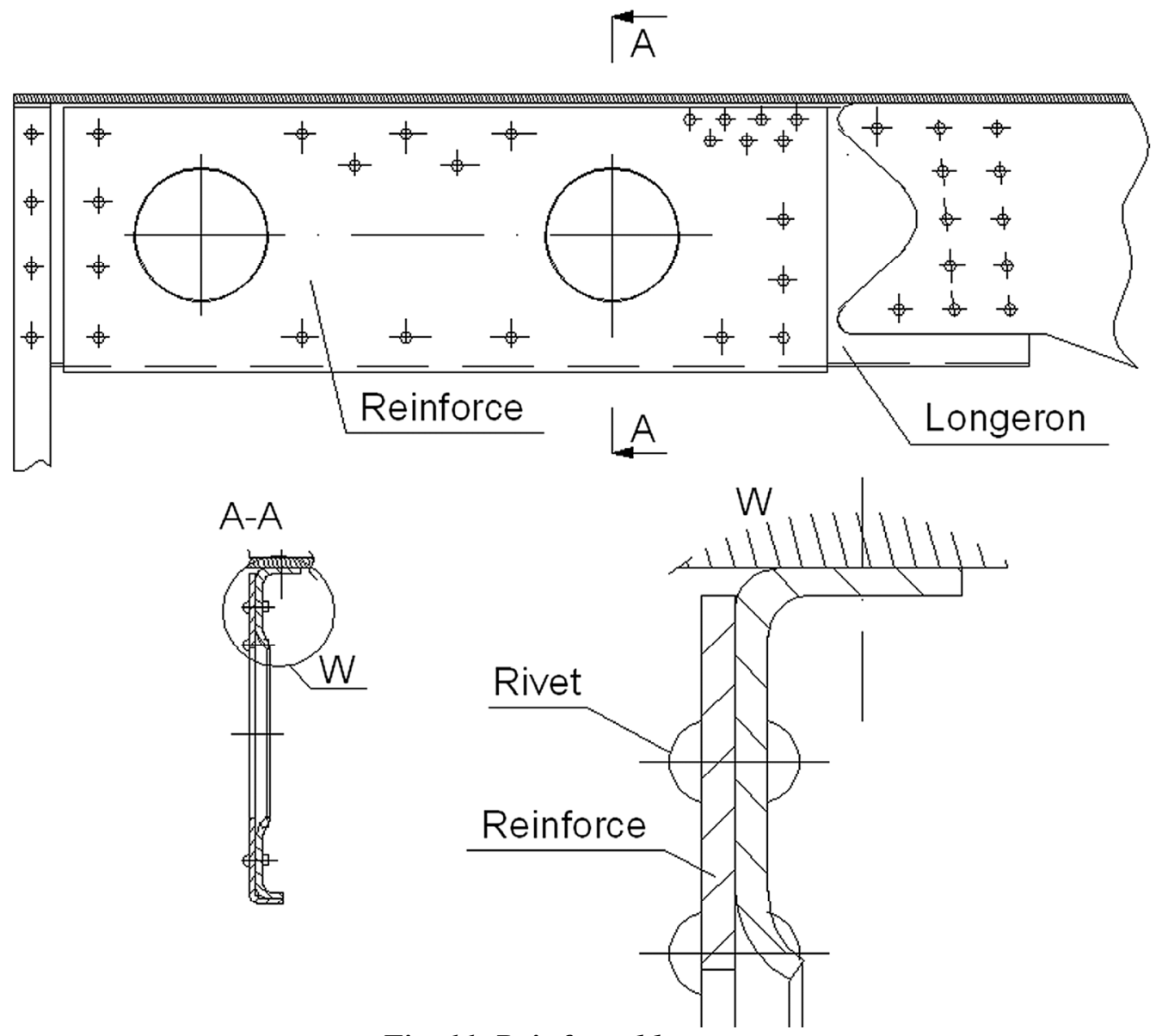

Fig. 11. Reinforced longeron

\section{MONITORING AFTER REPAIR}

The properties of the patch are always different from the original structure, so the panel must be monitored after repair.

In this case, the Nondestructive Testing Methods (NDT) used are based on the structure quality validation after repair. New methods called "Structural Health Monitoring" (SHM) enable checking the structure condition during exploitation. 


\section{REFERENCES}

[1] Dragan, K. \& Klimaszewski, S. (2006). In-service Flaw Detection and Quantification on the MiG-29 Composite Vertical Tail Skin, ECNDT.

[2] Roach, D., Moore, D., Walkington, P. (1996). Nondestructive Inspection of Bonded Composite Doublers for Aircraft, Sandia National Labs, FAA Airworthiness Assurance NDI Validation Center.

[3] Technical Manual. (2005). Nondestructive Inspection Methods, Basic Theory, T.O. 33B-1-1, NAVAIR 01-1A-16, TM 1-1500-335-23.

[4] Baker, A., Rose, F., Jones, R. (2002). Advances in the Bonded Composite Repair of Metallic Aircraft Structure. Oxford. ISBN 0-008-042699-9. 